\title{
Conflicts of interest: how money clouds objectivity
}

Richard Smith

J R Soc Med 2006;99:292-297

Richard Smith was editor of the BMJ and chief executive of the BMJ Publishing Group for 13 years. In his last year at the journal he retreated to a 15th century palazzo in Venice to write a book. This is a much shortened chapter from the author's book provisionally entitled The Trouble With Medical Journals that the RSM Press will publish in the autumn [www.rsmpress.co.uk], and this is the third in a series of extracts that will be published in the JRSM.

I want to begin this article with a fantasy, one that has a powerful hold in the minds of many. Doctors treat patients using simply the best evidence and their experience. They are not influenced by money or self interest. Similarly, researchers try to answer the important questions in medicine; specialist societies are concerned only with what is best for a population of patients; and editors of journals publish only what is true and important for medicine. Unlike people who work in the venal worlds of commerce, politics, or journalism we in healthcare are untainted by money and 'the pursuit', in the words of Sigmund Freud, '. . . of fame and the love of beautiful women (or perhaps men)'.

This is, of course, nonsense. Those who work in healthcare are human beings and just as prone as any other humans to acting in their own interest; responding to economic incentives, and stumbling into frank fraud and corruption. Anybody who has knocked around in the world and read Dante, Juvenal, Balzac and Dickens knows that this is how human beings behave. Yet somehow in medicine we have fallen prey to the fantasy that we are superhuman. We are not. We are exposed to conflicts of interest, like everybody else. Our response should not be to pretend that they do not exist, but rather to acknowledge and disclose them always - and sometimes to accept that they are so extreme that the doctor should not treat a particular patient or an author write an editorial in a medical journal.

\section{SCOPE FOR CONFLICTS OF INTEREST ARE GROWING}

Academia and industry are becoming increasingly entangled. In the USA industry support of biomedical research grew from a third in 1980 to almost two-thirds in $2000 .{ }^{1}$ In
1986 just under half of life science companies in the USA funded research in academic institutions. This had increased to $92 \%$ by 1996 . About two-thirds of universities in the USA invest in businesses that sponsor research in the same institutions. Meanwhile, pharmaceutical companies spend billions of dollars on the influencing, education, and entertainment of doctors around the world. The scope for conflicts of interest is vast.

\section{DEFINING CONFLICT OF INTEREST}

Conflict of interest has been defined as 'a set of conditions in which professional judgement concerning a primary interest (such as patients' welfare or the validity of research) tends to be unduly influenced by a secondary interest (such as financial gain)'. ${ }^{2}$ It is important to understand that it is a condition not a behaviour. Many doctors fail to declare a conflict of interest because they are confident that the conflict has not caused them to behave in a different way. This is to misunderstand conflict of interest. It is hard-perhaps impossible-for us to know whether the conflict of interest has caused us to behave in a different way. We do not always understand our own motivations. Double-blind randomized trials are so important, not because researchers are consciously dishonest, but because bias is pervasive and unconscious. It is the same, I suggest, with conflicts of interest.

\section{CONFLICTS OF INTEREST ARE ALMOST UNIVERSAL}

Conflicts of interest may be almost universal. Doctors in many countries are paid, at least in part, by what they do. If doctors are paid to perform investigations, to admit patients to particular hospitals, or to carry out treatments or investigations, then they have financial conflicts of interest. Similarly, if they have lunches bought for them by pharmaceutical companies, are paid as consultants by those companies, or have shares in those companies, then they have conflicts of interest. There are very few doctors who have not been given something by a pharmaceutical company.

A major review in $J A M A$ systematically collected all the evidence on financial conflict of interest in biomedical research and concluded that about a quarter of researchers have received research funding from the pharmaceutical industry. ${ }^{1}$ Whether or not people are deemed to have 
conflicts of interest obviously depends on the definition used; a survey in 1998 found that nearly half of researchers had received 'research-related gifts' - materials or money. ${ }^{3}$ An analysis of 789 articles from major medical journals found that a third of the lead authors had financial interests in their research - patents, shares, or payments for being on advisory boards or working as a director. These conflicts were mostly not disclosed to readers. ${ }^{4}$

A study in the New England Journal of Medicine looked at the financial conflicts of interest of authors of 75 pieces on calcium channel antagonists published in prominent medical journals. ${ }^{5}$ They asked the 89 authors of the articles whether they had received from pharmaceutical companies reimbursement for attending a symposium, fees for speaking, fees for organizing education, funds for research, funds for a member of staff, or fees for consulting. They also asked about the ownership of stocks and shares in companies. (The questionnaire used in the study and adapted for use by the BMJ can be viewed at [http://bmj.com/cgi/content/ full/317/7154/291/DC1]) Sixty-nine (80\%) of the authors responded, and 45 (63\%) had financial conflicts of interest. Yet in only two of the 75 pieces were the conflicts of interest disclosed. This is despite the fact that the uniform requirements for authors submitting articles to medical journals have required them to declare conflicts of interest since $1993 .{ }^{6}$

A study that I undertook with a medical student looked at 3642 articles in the five leading general medical journals (Annals of Internal Medicine, BMJ, Lancet, JAMA, and the New England Journal of Medicine) and found that only 52 (1.4\%) declared authors' conflicts of interest. ${ }^{7}$ One positive sign was that there was a trend towards more declarations over time.

Editors themselves, I must note, hardly ever declare their own conflicts of interest. The BMJ posted competing interest statements for the members of the editorial team, the editorial board, and the management team in 2003; but this was several years after it required authors and reviewers to declare their competing interests. A study of 37 general medical journals found that only nine had an explicit policy to deal with the editors' conflicts of interest and that the $B M J$ was the only journal that publicly declared the conflicts of interests of its editors and editorial board. ${ }^{8}$

\section{THE EFFECTS OF CONFLICT OF INTEREST}

Several studies have shown that financial benefit will make doctors more likely to refer patients for tests, operations, or hospital admission, ${ }^{9-11}$ or to ask that drugs be stocked by a hospital pharmacy. ${ }^{12}$ Caesarean section rates vary dramatically across the world and are higher when women are cared for by private practitioners who are paid for the operation. ${ }^{13,14}$ Doctors in Britain performed screening examinations on older people when paid to do so-even though most argued that there was no evidence to support such screening. Dentists in Britain carry out many unnecessary fillings because they are paid much more to fill teeth than to simply clean them. Doctors, in other words, do respond to financial incentives, and it would be surprising if they did not.

The JAMA review found 11 studies that compared the outcome of studies sponsored by industry and those not so sponsored. ${ }^{1}$ In every study those that were sponsored were more likely to have a finding favourable to industry. When the results were pooled the sponsored studies were almost four times more likely to find results favourable to industry. When we remember that industry sponsors about three quarters of the randomized trials in the major weekly journals, ${ }^{15}$ then we can see that there is substantial room for bias.

The study I have already quoted on calcium channel antagonists classified 70 articles from major journals as critical of the drugs (23), supportive (30), or neutral (17). Almost all supportive authors (96\%) had financial relationships with manufacturers, compared with $60 \%$ of neutral authors and $37 \%$ of critical authors. ${ }^{5}$

An important study from JAMA looked at what characteristics determined the conclusions of review articles on passive smoking. ${ }^{16}$ The authors identified 106 reviews, with $37 \%$ concluding that passive smoking was not harmful and the rest that it was. They then considered all the factors that might mean that authors of reviews reached different conclusions. One was the quality of the review. Perhaps better done reviews reached one conclusion and poorly done ones another. Another factor they considered was whether a journal was peer reviewed. It might be that journals that had peer review system would publish better reviews that reached the same conclusion. Or could it be the year of publication? Perhaps recent studies had changed the direction of the evidence. The authors of the JAMA study expected to find that the quality of the review would be the most important determinant of whether or not authors of reviews found that passive smoking was harmful.

In fact, the only factor associated with the review's conclusion was whether the author was affiliated with the tobacco industry. ${ }^{16}$ Three-quarters of the articles concluding that passive smoking was not harmful were written by tobacco industry affiliates. The study authors suggest that '...the tobacco industry may be attempting to influence scientific opinion by flooding the scientific literature with large numbers of review articles supporting its position that passive smoking is not harmful to health'. Again, only a minority of the articles (23\%) disclosed the sources of funding for research. The authors had to use their own database of researchers linked with the tobacco industry to determine whether authors had such links. ${ }^{17}$ 
This is a disturbing finding. It suggests that, far from conflict of interest being unimportant in the objective and pure world of science where method and the quality of data is everything, it is the main factor determining the result of studies.

\section{THE CONFLICTS OF INTEREST FACED BY EDITORS}

\section{Reprints}

Discussion of conflict of interest and journals rarely extends beyond authors and reviewers; the fact that all of us are much more interested in the conflicts of interest of others rather than our own conflicts means that we have little evidence on the prevalence, extent, and effects of editorial conflicts of interest. But the 'black box' of peer review leaves huge scope for conflicts of interest to have powerful effects.

The conflict of interest that seems to me most stark arises in relation to reprints of articles. Pharmaceutical companies will often spend thousands (and occasionally millions) of dollars buying reprints of single articles from journals. The company Merck reportedly bought a million reprints of the highly controversial VIGOR trial that suggested that its drug, rofecoxib, had fewer gastrointestinal side effects than naproxen. ${ }^{18}$ The companies usually buy reprints of studies that they have funded themselves. Unsurprisingly, they buy them only when the results are positive for their drugs, and they use these reprints as a form of marketing. They are given to doctors, and the prestige of the journal adds to the marketing message.

Editors know which sorts of articles are likely to be purchased as reprints by pharmaceutical companies. If they accept such an article then their journal may receive hundreds of thousands of dollars in income - and these reprints are very profitable. If they reject the article then the money is gone. Some editors are directly responsible for the budgets of their journals, and all editors are concerned about their budgets. A healthy budget means job security, praise from the owners, and often the freedom to expand and innovate. A failing budget means the opposite; and for many journals reprint income is an important source of revenue-sometimes the most important. Editors may be faced with a choice as stark as accepting a study that will bring a substantial income or making some editorial colleagues redundant in order to stay within budget. A million dollar order may mean US\$600 000 profit, which is the equivalent of several editorial salaries for a year.

Sometimes companies will ring when an article is submitted and make clear that they will purchase reprints if the article is accepted. This is effectively a bribe, and 'everybody has their price'. A woman from a public relations company once rang me at the $B M J$ to say that if we accepted a paper then she would 'take me to restaurant of my choice'. She was very effusive and stopped just short of saying she would go to bed with me if we took the paper. This was actually the most brazen bribe I was offered in 25 years as an editor. Readers will be relieved to know that the $B M J$ did not accept the paper.

I do not know how other editors handle this conflict of interest, but I think that the answer is that they reassure themselves that their judgement is not affected. The evidence that I have quoted on conflicts of interest in other contexts suggests that they are wrong. I was somewhat relieved of the conflict in that I rarely attended the meetings where the final decision was taken on which papers to publish. The $B M J$ was highly unusual (some would say irresponsible) in that the decisions on which original research papers to publish were taken largely by outside advisers. They had no responsibility for the budget, and most (at least until reading this book) were unaware of the money attached to reprints.

\section{Advertising}

Another conflict of interest for editors relates to advertising - a major source of income for many journals. Most of the advertising comes from pharmaceutical companies. Advertisers would always prefer an editorial plug to an advertisement - because they know that readers discount advertising. They want to tie advertising and editorial material as closely together as possible and have various ways to do this. Advertisers may also object to particular studies and withdraw-or threaten to withdraw-their advertising. This may mean death for some journals, and editors may be faced with the stark choice of agreeing not to publish a particular piece or seeing their journal die.

The BMJ faced something close to this with one of the local editions of the journal (selections from the weekly BMJ published in around a dozen different countries). The local edition was heavily dependent on advertising and just breaking even. One company which bought advertising threatened to withdraw it if the local edition republished an article that had been published in the weekly BMJ and had been critical of the company and one of its products. For the staff, including the business staff, in London this was an easy decision — what the Americans call a 'no brainer'. If the $B M J$ had succumbed to such pressure there would be no point in publishing the local edition and - worse still - the independence of the weekly edition, perhaps its greatest attribute, would be undermined. It was not so easy for the local publishers, who stood to lose their investment and damage their relationship with an important customer who bought advertising space in their other publications. But the $B M J$ stood firm and published the article. (The local edition 
did not die at that point but did later through lack of income from advertising.)

In 2004 the BMJ devoted the whole issue to the relationship between doctors, including their journals, and the pharmaceutical industry. ${ }^{19}$ The cover of the journalwhich summed up the whole issue for many-showed doctors as pigs gorging at a banquet and playing golf with the drug company representatives as lizards; a patientdepicted as a guinea pig - sat amazed at the whole escapade. The BMJ's target was more doctors than drug companies, but the companies were very upset and threatened to withdraw $£ 750000$ of advertising. As far as I can tell, they did not: it is impossible to know for sure because you cannot know exactly what they were intending to spend.

\section{Business}

A financial conflict of a different form for editors and journals arises in relation to allowing their studies to be posted on electronic databases - like Pubmed Central - that allow everybody free access. If the journals and their owners are primarily interested in advancing science and medicine, as most medical organizations claim to be, then surely the material should be made available for freeparticularly as most of the cost of generating it, the research costs, have been met with public money. But making material available for free may cause a loss of subscriptions to the journal-and so reduce profits and perhaps ultimately kill the journal.

Most editors and journals have dealt with this conflict by not recognizing it. Most have stayed with the status quo and declined to make their studies available on PubMed Central. This issue illustrates how there is constant conflict between what might be best editorially and financially. This is analogous to the conflict between what doctors and patients might want to do, given unlimited resources and what can be afforded. Some argue that the best way to resolve the conflict is for editors (and by analogy doctors) to have no responsibility whatsoever for money. This responsibility should lie with somebody else-owners, publishers, or managers.

The trouble with this 'solution' is that it leads to constant - and often increasingly bitter - battles. The conflict between editorial (or medical) and financial needs is real. It cannot be avoided. It has to be resolved, and if the conflict is institutionalized in different individuals or parts of the organization it is not resolved efficiently and effectively. Rather, much grief is generated. I think it better that one individual (the editor) or one team have responsibility for both editorial quality (or medical excellence) and finance. The conflicts can then be resolved within the individual or team. We are all used to doing this in our daily lives. If I want to make a journey I trade off comfort, speed, and cost - and perhaps travel standard class on a train. But if I did not have to think at all about cost I might charter a plane or at least travel first class.

\section{RESPONDING TO CONFLICTS OF INTEREST}

The greatest difficulty with conflict of interest is to know how to respond. It is impossible to eradicate conflicts of interest. They are part of life. The New England Journal of Medicine did try to have its editorials written only by doctors without any conflicts of interest. One result was that the editors had great difficulty finding authors to write on some subjects. Within some medical specialties - rheumatology and dermatology, for example - it is impossible to find anybody who does not have a conflict of interest. The BMJ once snootily dismissed a television programme by saying that it was full of people with vested interests. The producer wrote and, rightly, pointed out that the only people who do not have vested interests are those who do not know anything about a subject - and what would be the point of having them on the programme. (This always reminds me of another correct aphorism that 'the only people who don't have personality disorders are people who don't have personalities'.)

Another result of the policy of the New England Journal of Medicine was that sometimes editorials were written by people with conflicts of interest, but readers - and editors - did not know. The editors were embarrassed when the Los Angeles Times published a piece entitled 'Medical journal may have flouted own ethics 8 times'. ${ }^{21}$ The journalist had identified eight cases where editorials had been written by authors with undeclared conflicts of interest. The journal has now changed its policy and allows editorials from authors who have a financial conflict below US\$10 000.22 The policy states:

'The key provision of the definition sets an upper limit on the annual sum that a person may receive before a relationship is automatically considered significant (the limit, currently $\$ 10,000$, is referred to as the de minimis level). We also regard as a significant interest any holding in which the potential for profits is not limited, such as stock, stock options, and patent positions.'

This too, I fear, will be hard to enforce. Measuring the size of a financial conflict is hard. But to its credit the journal has tried to grasp the nettle of defining when a conflict is so large that the person must be excluded. The $B M J$ had not done that in my time as editor.

A more common policy is to ask people to declare conflicts of interest. Those sitting on government committees must declare conflicts. In some circumstances doctors treating patients are required to declare conflicts- 
for example, telling patients that they are receiving a payment for entering them into a post-marketing trial of a drug or that they have a financial interest in the hospital to which they are referring them. Mostly, however, doctors do not declare conflicts of interest to patients.

Most journals are moving towards asking authors and reviewers to declare conflicts of interest. The BMJ asks all authors and reviewers to complete a questionnaire on conflicts of interest, and authors' statements are published. ${ }^{23}, 24$ The editors started years ago to try and encourage authors to declare conflicts of interest by sending everybody a form describing what they meant by conflicts of interest and asking authors to let them know if they had any. Few people declared conflicts of interest, as the research showed. But research also showed that most people had them. Why were they not being declared?

One reason is that the culture was not to declare them. It was not an issue that doctors thought important. That is now changing. People also did not declare conflicts of interest because they were confident that they were not influenced by them - in the same way that most of us, and certainly most doctors, are confident that we are not influenced by advertising. 'Other people must beotherwise advertisers wouldn't bother-but I'm not.' I suspect, too, that authors and reviewers thought that it was in some way 'naughty' to have a conflict of interest. By declaring a conflict you suggested that you had been 'bought'. I believe that it is by no means naughty to have a conflict of interest but it is not to declare one.

The $B M J$ changed its policies in order to try and get more authors and reviewers to declare conflicts of interest. First, it changed the phrase from 'conflicts of interest' to 'competing interests'. This, the editors hoped, would reduce the feeling of 'naughtiness'. Secondly, the journal abandoned requiring people to declare non-financial conflicts. Thirdly, authors and reviewers were sent a specific questionnaire that authors have to complete. The form was derived from that used in the study on calcium channel blockers, ${ }^{5}$ and its asks specifically about shares, employment, reimbursement for attending a meeting, fees for speaking, and funds for a member of staff, research, consulting, or organising education.

Whatever the reason, many more authors and reviewers do now declare a competing interest. ${ }^{25}$ The culture seems to have changed, and it has become acceptable and normal - at least within the $B M J$ - to declare competing interests. The journal started with original papers but slowly extended the practice to every part of the journal. Letters to the editor - for the BMJ and other journals - have been a hotbed of conflict of interest. Many authors who described themselves simply as doctors had close links with pharmaceutical companies and were often prompted by the companies to write. Almost all letters to the editor to the
$B M J$ now arrive electronically, and the software will only allow submission of the letter if authors either declare a competing interest or click to say they do not have one.

The BMJ's policy is 'if in doubt, declare'. Problems rarely flow from declaring conflicts of interest, but they do arise when they are discovered to exist when not declared. We live in a world, whether we like it or not, where what is not transparent is assumed to be biased, corrupt, or incompetent until proved otherwise.

Disclosure alone cannot solve the problem of conflict of interest. Clearly, some conflicts are so extreme that they preclude a person from writing or reviewing. Thus, a journal would not commission an editorial on a drug from somebody employed by the manufacturer of the drug. Nor would a journal ask an author to review his sister's book. But where is the cut off point? Most journals have not been explicit about where it is - but they surely should be.

Problems remain even with the policy of disclosure. ${ }^{25}$ Reviewers' conflicts are not published because reviewers are not named in most journals. The BMJ was planning to do so when I left and then it would have disclosed reviewers' competing interest. But the BMJ remains highly unusual with its policy of open review, and it would seem odd to disclose the reviewers' conflicts of interest if their names were not disclosed. Next, journals usually do not give information on the scale of the financial competing interest. It might be that an author was bought a cheese sandwich by a company, or that he has a sizeable vineyard funded from consulting fees. I think it likely that the scale of the competing interest is important, but it would be a bold step to require it - especially in Britain where people find it even more difficult to talk about their financial affairs than their sex lives. Then, journals should surely at some time try again with requiring people to declare non-financial competing interests.

\section{CONCLUSION}

Conflicts of interest are common in healthcare, and yet, until recently, they have rarely been declared. We have increasing evidence that conflicts of interest affect behaviours like the referral of patients and the interpretation of the results of studies. Editorial conflicts of interest may be particularly stark, and yet they are largely unstudied. Readers seem to discount studies where conflicts of interest are declared, but much more research is needed to understand this more fully. The best response to conflicts of interest seems to be disclosure rather than attempted eradication; but sometimes conflicts of interest will be so strong that they will rule people out from actions like referring patients or writing editorials. The bigger problem of profound bias within trials conducted by pharmaceutical companies cannot be solved by journals. 


\section{REFERENCES}

1 Bekelman JE, Li Y, Gross CP. Scope and impact of financial conflicts of interest in biomedical research: a systematic review. JAMA 2003;289: 454-65

2 Thompson DF. Understanding financial conflicts of interest. N Engl J Med 1993;329:573-6

3 Campbell EG, Louis KS, Blumenthal D. Looking a gift horse in the mouth: corporate gifts supporting life sciences research. JAMA 1998;279:995-9

4 Krimsky S, Rothenberg LS, Stott P, Kyle G. Scientific journals and their authors' financial interests: a pilot study. Sci Eng Ethics 1996;2: 395-410

5 Stelfox HT, Chua G, O'Rourke K, Detsky AS. Conflict of interest in the debate over calcium channel antagonists. N Engl J Med 1998;338: $101-5$

6 International Committee of Medical Journal Editors. Conflict of interest. Lancet 1993;341:742-3

7 Hussain A, Smith R. Declaring financial competing interests: survey of five general medical journals. BMJ 2001;323:263-4

8 Haivas I, Schroter S, Waechter F, Smith R. Editors' declaration of their own conflicts of interest. Can Med Assoc J 2004;171:475-6

9 Wilkinson P. "Self referral": a potential conflict of interest. BMJ 1993; 306:1083-4

10 Hillman BJ, Joseph CA, Mabel MR, Sunshine JH, Kennedy SD, Noelher M. Frequency and costs of diagnostic imaging in office practice: a comparison of self referring and radiologist referring physicians. N Engl J Med 1990;323:1504-8

11 Hillman AI, Pauly MV, Kerslein B. How do financial incentives affect physicians' clinical decisions and the financial performance of health maintenance organisations. N Engl J Med 1989;321:86-92
12 Chren MM, Landefeld CS. Physicians' behaviour and their interactions with drug companies. JAMA 1994;271:684-9

13 Murray SF. Relation between private health insurance and high rates of caesarean section in Chile: qualitative and quantitative study. BMJ 2000;321:1501-5

14 Roberts CL, Tracy S, Peat B. Rates for obstetric intervention among private and public patients in Australia: population based descriptive study. BMJ 2000;321:137-41

15 Egger $M$, Bartlett $C$, Jüni $P$. Are randomised controlled trials in the BMJ different? BMJ 2001;323:1253

16 Barnes DE, Bero LA. Why review articles on the health effects of passive smoking reach different conclusions. JAMA 1998;279:1566-70

17 Barnes DE, Bero LA. Industry funded research and conflict of interest: an analysis of research sponsored by the tobacco industry through the Center for Indoor Air Research. J Health Policy Law 1996;21:515-42

18 Bombardier C, Laine L, Reicin A, et al. Comparison of upper gastrointestinal toxicity of rofecoxib and naproxen in patients with rheumatoid arthritis. N Engl J Med 2000;343:1520-8

19 Abbasi K, Smith R. No more free lunches. BMJ 2003;326:1155-6 [http://bmj.bmjjournals.com/cgi/content/full/326/7400/1155] Accessed 7 March 2006

20 Monmaney T. Medical journals may have flouted own ethics 8 times. Los Angeles Times 199921 October

21 Drazen JM, Curfman GD. Financial associations of editors. N Engl J Med 2002;346:1901-2

22 Smith R. Beyond conflict of interest. BMJ 1998;317:291-2

23 Smith R. Conflict of interest and the BMJ. BMJ 1994;308:4

24 Smith R. Making progress with competing interests. BMJ 2002;325: $1375-6$ 